\title{
The Modifying Role of Pregnancy on Ophthalmological and Neuro-ophthalmological Diseases
}

\author{
Henry Liu ${ }^{1}$, Yiu-chia Chang ${ }^{1}$, Xiang $\mathrm{Ji}^{2}$ \\ ${ }^{1}$ Faculty of Medicine, University of Ottawa \\ ${ }^{2}$ Institute of Medical Science, University of Toronto
}

\section{ABSTRACT}

The female visual system experiences a series of physiological modifications during pregnancy, and these changes have profound implications on many general ophthalmological and neuro-ophthalmological disorders, exacerbating some conditions while alleviating others. Patients with open-angle glaucoma experience improved disease states, with accompanying normal visual fields. Uveitis and MS-induced optic neuritis exhibit decreased rates of occurrence. Non-proliferative diabetic retinopathy initially worsens with gestation, eventually improving in the post-partum state with only $5 \%$ of cases progressing into the proliferative stage. As for idiopathic intracranial hypertension, existing symptoms worsen during pregnancy. Therapeutic interventions such as immunosuppressants, anti-neoplastic drugs, and steroids administered prophylactically during fetal development may lead to potential teratogenic outcomes manifesting in devastating birth defects and should be administered with caution.

RÉSUMÉ

Le système visuel féminin subit une série de modifications physiologiques pendant la grossesse, et ces changements ont des implications profondes sur de nombreux troubles ophtalmologiques et neuro-ophtalmologiques généraux, exacerbant certaines conditions tout en soulageant d'autres. Les patients atteints de glaucome à angle ouvert ont une amélioration des états pathologiques, accompagnés de champs visuels normaux. L'uvéite et la névrite optique induite par la SEP présentent des taux d'occurrence réduits. La rétinopathie diabétique non proliférative s'aggrave au début avec la gestation, s'améliorant finalement dans l'état post-partum avec seulement $5 \%$ des cas progressant dans le stade prolifératif. En ce qui concerne l'hypertension intracrânienne idiopathique, les symptômes existants s'aggravent pendant la grossesse. Les interventions thérapeutiques comme les immunosuppresseurs, les médicaments antinéoplasiques et les stéroïdes administrés de façon prophylactique pendant le développement du fotus peuvent entraîner des effets tératogènes potentiels se manifestant par des malformations congénitales dévastatrices et doivent être administrés avec prudence.

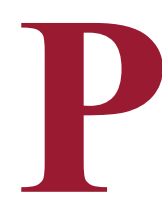

regnancy induces a plethora of physiological changes to a woman's eyes that are often transient but can persist well past the post-partum period [1]. In the anterior segment, there is a temporary reduction in corneal sensitivity in pregnant women from edema-induced corneal thickening [1]. Moreover, a decrease in intra-ocular pressure (IOP) is observed due to increased aqueous outflow, diminished episcleral venous pressures, and reductions in scleral rigidity [1]. Systemically, a pregnant mother's body undergoes immunologic changes, where the maternal immune system is biased towards a $\mathrm{TH} 2$ humoral response since $\mathrm{TH} 2$ cytokines protect the fetus at the maternal-fetal interface [2]. In addition, T-regulatory cells elevate their activity levels at the maternal-fetal interface, which is essential to achieve adequate immunosuppression to prevent an unwanted attack on the fetus [2]. Due to the aforementioned physiological alterations, certain ocular conditions can be ameliorated while others may be exacerbated (see summary in Table 1). The purpose of this article is to review the modifying role of pregnancy for the most common ophthalmological and neuro-ophthalmological diseases observed in clinical practice: glaucoma, uveitis, diabetic retinopathy, idiopathic intracranial hypertension, and optic neuritis. Approaches and precautions to management will also be provided in light of the potential adverse effects of ocular medications on the mother and developing fetus.

\section{GLAUCOMA}

Primary open-angle glaucoma, a disease affecting approximately $2-3 \%$ of the population over the age of 40 , is often associated with elevated IOP, which ultimately leads to a progressive deterioration of the optic nerve [3]. Though advanced age is a strong risk factor, glaucoma can occasionally be seen

Keywords: Pregnancy; Ophthalmology; Teratogenicity; Neuro-Ophthalmology 
Table 1. The effect of pregnancy on common general ophthalmological and neuro-ophthalmological diseases during pregnancy.

\begin{tabular}{|l|l|}
\hline \multicolumn{1}{|c|}{ Condition } & \\
\hline Glaucoma & $\begin{array}{l}\text { Variable outcome despite } \downarrow \text { IOP during gestation [7]: } \\
\text { Effects During Pregnancy }\end{array}$ \\
\hline Uveitis & $\quad 18 \%$ reported stable IOPs \& normal visual fields \\
\hline Diabetic Retinopathy & Decreased rate of uveitis flare-ups [11] \\
\hline $\begin{array}{l}\text { Idiopathic Intracranial } \\
\text { Hypertension }\end{array}$ & $\begin{array}{l}\text { Exacerbation of non-proliferative DR improves by 3rd trimester with 5\% risk of progression into proliferative } \\
\text { DR [17] }\end{array}$ \\
\hline $\begin{array}{l}\text { Optic Neuritis/Multiple } \\
\text { Sclerosis }\end{array}$ & Symptoms may worsen during pregnancy with notable weight gain [28] \\
\hline
\end{tabular}

in women of childbearing age [3]. These women, for instance, may have previously acquired glaucoma either congenitally, through early childhood (anterior segment dysgenesis or cataract extraction), or from coexisting ocular conditions (uveitis or diabetes) [3].

It is well-evidenced that IOP decreases significantly during pregnancy $[1,4]$. Glaucoma symptoms such as blurred vision and pressure-induced ocular pain in women with pre-existing primary open-angle glaucoma may demonstrate improvement throughout the later course of gestation, with mean IOP of first trimester patients being $2 \mathrm{mmHg}$ higher than those during the third trimester [5]. IOP reductions can transiently decrease up to $10 \%$ for several months post-partum [4]. An interplay of decreased episcleral venous pressures from lowered peripheral vascular resistance, higher aqueous outflow facilitated by hormonal changes in progesterone and relaxin, and the development of mild metabolic acidosis has been proposed as mechanisms for the reduction in IOP [6]. However, the extent to which the decrease in IOP can be protective of glaucoma progression is still highly contentious. The largest retrospective trial examining pregnant women with pre-existing glaucoma reported stable IOPs and visual fields in $57 \%$ of eyes, while $18 \%$ experienced stable or increase in IOP with progressive visual field loss [7]. This study demonstrated that the course of glaucoma is highly variable despite reductions in IOP. Hence, it is advisable for pregnant patients to receive active monitoring of ocular pressures and visual field deficits.
The management of open-angle glaucoma during pregnancy presents a multitude of ethical and legal challenges. One questionnaire conducted by Vaideanu and Fraser [8] revealed that $31 \%$ of ophthalmologists are uncertain of how to handle such cases while only $26 \%$ reported having treated pregnant women. Presently, only the FDA category B agent, brimonidine, an a2 agonist, is considered safe and based solely from experimental animal studies [6]. Other foundational medications for glaucoma, including beta blockers, carbonic anhydrase inhibitors, and prostaglandin analogues, present uncertain safety risks and potential adverse effects in human and animal trials [9] (see Table 2 for a list of teratogenic effects from ocular medications). Laser trabeculoplasty may be a feasible alternative to the use of medications for the treatment of glaucoma during pregnancy, with the drawback of prolonged time to therapeutic onset and reduced efficacy in younger patients [9]. Surgical intervention may be warranted following persistent relapse after conventional medical and laser therapy.

\section{UVEITIS}

Uveitis involves inflammation of the uvea, consisting of the iris, ciliary body, and choroid [10]. The estimated prevalence of uveitis is 120 adults out of 100,000 , representing $10 \%$ of irreversible blindness [10].

Research has demonstrated that the probability of uveitis flare-ups was reduced during pregnancy in comparison to 3 months prior to pregnancy and 6 months post-partum [11]. Furthermore, one retrospective chart review by Chiam et al. 
Table 2. The teratogenic effects of known pharmacological interventions for common general ophthalmological and neuroophthalmological conditions.

\begin{tabular}{|c|c|c|}
\hline Condition & Therapeutic Interventions & Teratogenicity \\
\hline Glaucoma & $\begin{array}{l}\text { Brimonidine ( } \alpha 2 \text { agonist) } \\
\text { Prostaglandin analogues } \\
\text { Timolol ( } \beta \text {-blocker) } \\
\text { Brinzolamide (Carbonic anhydrase inhibitor) }\end{array}$ & $\begin{array}{l}\text { Safe to administer based solely on animal studies [6] } \\
\text { Uncertain safety risks from human \& animal trials [9] } \\
\text { Risks of infantile apnea, cardiac arrhythmia [52] } \\
\text { Fetal body weight [53] }\end{array}$ \\
\hline Uveitis & $\begin{array}{l}\text { Methotrexate (Folic acid antagonist) } \\
\text { Cyclophosphamide (Antineoplastic) } \\
\text { Mycophenolate mofetil (Immunosuppressant) } \\
\text { Azathioprine (Immunosuppressant) } \\
\text { Cyclosporine (Immunosuppressant) }\end{array}$ & $\begin{array}{l}\text { Skull defect, CNS abnormality, limb, GI, and cardiopulmonary defects [54] } \\
\text { Potential ear and eye abnormalities; absent thumb and cleft palate [55] } \\
\text { Microtia, cleft palate, heart defects and diaphragmatic hernia [15] } \\
\text { May contribute to risks of prematurity [12] } \\
\text { May contribute to risks of prematurity [56] }\end{array}$ \\
\hline $\begin{array}{l}\text { Diabetic } \\
\text { Retinopathy }\end{array}$ & $\begin{array}{l}\text { Ranibizumab (Antibody Fab fragment, Anti- } \\
\text { VEGF) } \\
\text { Aflibercept (Anti-VEGF) }\end{array}$ & $\begin{array}{l}\text { Low risks of fetal skeletal defects at specific dosage [57] } \\
\text { Potential risks of fetal malformation [57] }\end{array}$ \\
\hline $\begin{array}{l}\text { Idiopathic } \\
\text { Intracranial } \\
\text { Hypertension }\end{array}$ & $\begin{array}{l}\text { Thiazide Diuretics } \\
\text { Acetazolamide (Carbonic anhydrase inhibitor) } \\
\text { Steroids } \\
\text { Meperidine (Opioid analgesic) } \\
\text { Acetaminophen with codeine (Opioid } \\
\text { analgesic) }\end{array}$ & $\begin{array}{l}\text { Risks to metabolism and smooth muscle function [57] } \\
\text { No clear evidence of teratogenicity during human pregnancy [58] } \\
\text { Weight gain, hyperglycemia, fetal development disruptions [23] } \\
\text { Risks of negatively affecting the fetal heart rate [55] } \\
\text { Risks of respiratory depression and dependence in the newborn following } \\
\text { codeine administration [57] }\end{array}$ \\
\hline $\begin{array}{l}\text { Optic } \\
\text { Neuritis/ } \\
\text { Multiple } \\
\text { Sclerosis }\end{array}$ & $\begin{array}{l}\text { Glatiramer Acetate (Immunomodulator) } \\
\text { Natalizumab (Monoclonal antibody) } \\
\text { Mitoxantrone (Antineoplastic) } \\
\text { Teriflunomide }\end{array}$ & $\begin{array}{l}\text { No association with teratogenicity [48] } \\
\text { Risks of spontaneous abortion and birth defects [59] } \\
\text { Risks of congenital heart failure, fetal growth defects [57] } \\
\text { No clear evidence of teratogenicity [60] }\end{array}$ \\
\hline
\end{tabular}

[12] showed that in 47 patients with a history of non-infectious uveitis, the course of uveitis changed during different stages of pregnancy, falling starting from second trimester and reaching a nadir in third trimester. However, the severity of uveitis flare-ups (as quantified by cell count in the anterior chamber) did not differ between the pregnant versus non-pregnant period [13]. The primary explanation for the quiescence in rate of flare-up is that pregnancy promotes anti-inflammatory cytokines, thus inhibiting the cell-mediated autoimmunity against the semiallogeneic fetus [14]. Recent evidence by Chan el al.
[14] has also suggested that elevated levels of estrogen and progesterone can aid the immune process in upregulating Th2-associated cytokines (IL4, IL5 and IL10) and downregulating Th1-mediated immunity (interferon gamma, IL12 and P40), both of which are predominantly involved in non-infectious uveitis. Moreover, increased activity of factors such as regulatory $\mathrm{T}$ cells, immunosuppressive cytokines, alpha-fetoprotein, and melanocyte-stimulating hormone have been shown to interact with Th2-mediated immunity in a multifactorial manner [14]. Interestingly, these immunosuppressive effects are typi- 
cally reversed within one to two months post-partum [14].

The management of non-infectious uveitis involves the use of immunosuppressive agents which may exert adverse effects on the fetus [15]. The majority of these medications, including methotrexate, cyclophosphamide, and mycophenolate mofetil (MMF), are not recommended for use during pregnancy due to potential teratogenic risks [15]. Furthermore, there is limited evidence for the use of monoclonoal antibody biologics such as rituximab and infliximab, and interleukin-1 receptor antagonist anakinra, but immunosuppressive agents such as azathioprine and cyclosporine may be administered under careful surveillance [16]. As advised by Wakefield et al. in a review of the management of uveitis during pregnancy [16], expected mothers should be counselled on the risks of infertility, miscarriage, and potential teratogenicity of immunosuppressive medications, so that treatment can be tailored by evaluating the risk of harm for both the mother and child.

\section{DIABETIC RETINOPATHY}

Diabetic retinopathy (DR) is a common microvascular complication from diabetes involving vasodegenerative changes that eventually result in areas of retinal ischemia [17]. This condition is one of the leading causes of preventable blindness in the working population (between 24 and 64 years) with a prevalence of $35 \%$ in patients with diabetes [17]. DR has been shown to be aggravated by pregnancy and the risk for progression has been associated with poor metabolic control at conception, severity of retinopathy at baseline, longer duration of diabetes, and coexisting hypertension [17]. DR is often classified into two types, non-proliferative DR representing background retinopathy and fluid leakage from vessels, and proliferative DR involving neovascularization [17].

Interestingly, studies have consistently demonstrated that approximately half of patients with non-proliferative DR experience symptom exacerbations that improve by the third trimester and post-partum, with $5 \%$ transitioning into proliferative DR [17-20]. According to the Diabetes Control and Complications Trial [19], pregnant women treated for diabetes were at 2.48 higher risk of exacerbations of their background retinopathy in comparison to non-pregnant women.

Despite some studies citing exacerbations of DR following strict glycemic control [21,22], maintaining a normal blood glucose level in long-term follow-up is considered beneficial. Specifi- cally, the normalization of glycemic levels has been linked with successful pregnancies as high levels of glucose can be teratogenic to the fetus, resulting in 39\% of preterm deliveries and $9 \%$ of intrauterine growth restrictions [21]. Laser therapy such as pan-retinal photocoagulation (PRP) is an effective mainstay of therapy, eliminating proliferative DR as a previously labeled contraindication for pregnancy [17]. Recently, anti-VEGF factors such as ranibizumab and Aflibercept have emerged as effective alternative therapies for DR [17]. In fact, evidence suggests the use of bevacizumab (an anti-VEFT factor) in combination with PRP was effective in the regression of new vessels and improvement of macular edema in patients with DR [20]. Nevertheless, prompt detection and treatment of proliferative DR is crucial. One study demonstrated that in a group of 81 patients with proliferative DR not treated prior to pregnancy, 47 (58\%) progressed, while in a group of 35 patients who had received laser photocoagulation prior to pregnancy, only 9 (26\%) progressed, suggesting that prepartum examination and management can be favourable on the outcome of proliferative DR [18]. Additionally, the use of scatter laser treatment is indicated during pregnancy in the presence of active neovascularization to prevent the development of vitreous haemorrhage in the second stage of labour [18]. Overall, young women with diabetes should be counselled and managed prior to their pregnancy with regular ophthalmological evaluations for continual monitoring [17].

\section{IDIOPATHIC INTRACRANIAL HYPERTENSION (IIH)}

Idiopathic intracranial hypertension (IIH), also known as pseudotumor cerebri, is a condition of unknown etiology characterized by increased intracranial pressure without hydrocephalus or mass lesion, and with normal cerebrospinal fluid (CSF) composition [23]. IIH predominantly affects obese women of childbearing age, with a prevalence of 19.3 per 100,000 [24]. The pathogenesis of IIH has not been fully elucidated, but is thought to be caused by disordered CSF dynamics [25]. Common symptoms include headaches and visual disturbances, including transient visual obscuration, visual field loss, and reduction of central visual acuity [26].

A study conducted by Digre et al. summarizing 109 cases of IIH established that this condition does not exhibit increased rate of occurrence in pregnant patients than in the non-pregnant counterparts of comparable age [27]. However, in agreement with the association between weight gain and IIH [28], symptoms of existing $\mathrm{IIH}$ tend to worsen during pregnancy. As demonstrated by Koontz et al. [29], 4 out of 9 pregnant women 
reported that their headaches intensified, with one of them experiencing increased loss of visual acuity simultaneously. In addition, in their study of 11 pregnancies, Katz et al. [30] showed that symptoms of $\mathrm{IIH}$, including headache and visual changes, were exacerbated in 9 pregnancies. Fortunately, many studies have shown that, with proper management, the symptoms of IIH improve or resolve rapidly post-partum or after termination of pregnancy [29-31]. Moreover, the outcome of visual acuity and visual field of pregnant women with $\mathrm{IH}$ is similar to that of the non-pregnant patients [31].

In general, treatment of IIH is similar for both non-pregnant and pregnant patients and is aimed at alleviating symptoms- mainly headache and visual obscuration- and preserving vision as blindness may develop in 10\% of pregnant patients [32]. Given the strong association between weight gain and $\mathrm{IIH}$, limiting weight gain to 20lbs and a nonketogenic diet are recommended for weight control $[31,33]$. Among the available diuretics, loops and thiazide diuretics should be avoided due to their adverse effects on the fetus, while acetazolamide, a carbonic anhydrase inhibitor capable of reducing intracranial pressure can be used after 20 weeks of gestation [34]. Steroids have undesirable side effects such as weight gain, hyperglycemia, and disruption of fetal development, and are therefore only indicated in acute settings to treat significant visual decline [23,33]. As for the analgesics available to treat headaches, meperidine and acetaminophen with codeine are recommended for short-term use, while propranolol and topiramate can be used prophylactically for severe intractable headache [33]. If vision continues to deteriorate despite the aforementioned medical therapies, surgical procedures must be considered, which include optic nerve sheath fenestration or decompression, and CSF shunts [23].

\section{OPTIC NEURITIS AND MULTIPLE SCLEROSIS}

Multiple sclerosis (MS) is an autoimmune disorder causing demyelination of nerve cells [35]. Optic neuritis, a condition where destruction of myelin sheath of the optic nerve causes acute, usually monocular vision loss, is highly associated with MS [35,36]. Two-thirds of cases of optic neuritis occur in women and it typically develops in patients between the ages of 20 to 40 [37-39]. The incidence of optic neuritis is greatest in countries of higher latitude such as the U.S., where annual incidence is estimated to be as high as 6.4 per 100,000 [35,40]. Common symptoms include a decline in vision typically over a 7 to 10 day period and painful ocular movement in the affected eye
$[41,42]$.

Due to the immunosuppressive state of pregnancy, disease activity and frequency of MS relapses decrease [46]. This finding was most clearly demonstrated in a large-scale prospective study which included 269 pregnancies in 254 women with MS [46]. Relapse rate was lower throughout pregnancy and fell substantially during the third trimester, reaching $30 \%$ of the pre-pregnancy state [46]. This suppression of MS relapse during pregnancy has been substantiated in other prospective clinical trials and MRI data [43-45]. During the first 3 months of postpartum period, multiple studies have shown that rate of exacerbation rebounds may exceed the pre-pregnancy levels, further underlying the protective role of pregnancy $[37,33,46,47]$.

Caution should be exerted when treating pregnant MS patients, as many medications may have adverse effects on the fetus. Among the disease-modifying agents, which are aimed at reducing the number of relapses, glatiramer acetate is considered most favorable as there was no association found with low birth weight, congenital anomaly, premature birth, or spontaneous abortion in a recent systematic review of 97 cases [48]. However, other disease-modifying drugs- including interferon-beta, natalizumab, fingolimod, mitoxantrone, and teriflunomide-are found to cause one or more of the following: preterm birth, spontaneous abortion, fetal hematological abnormalities, congenital anomalies $[49,50]$. Standard symptomatic treatment for acute relapse is high-dose glucocorticoids given daily for 3 to 7 days [51]. There have been reports that steroids increase risk of cleft palate and lower birth weight in the first trimester, but it is generally safe for short-term use in second and third trimesters [51].

\section{CONCLUSION}

Pre-existing general ophthalmological and neuro-ophthalmological conditions may be exacerbated or ameliorated due to a variety of physiological changes induced during pregnancy. Diseases that tend to worsen with gestation include diabetic retinopathy and $\mathrm{IH}$, whereas glaucoma, uveitis, and MS-induced optic neuritis may improve. Treatment of most of these diseases is similar to that for the non-pregnant patients, although one should take into consideration the teratogenic profile of the treatment and conduct therapy with caution. Through familiarity with these possible neuro-ophthalmological changes and the available treatment options, physicians will be able to provide better eye care for their pregnant patients. 


\section{REFERENCES}

1. Grant AD, Chung SM. The eye in pregnancy: ophthalmologic and neuro-ophthalmologic changes. Clinical obstetrics and gynecology. 2013;56(2):397-412.

2. Wegmann TG, Lin H, Guilbert L, Mosmann TR. Bidirectional cytokine interactions in the maternal-fetal relationship: is successful pregnancy a TH2 phenomenon?. Immunology today. 1993;14(7):353-6.

3. Sharma S, Wuntakal R, Anand A, Sharma TK, Downey G. Pregnancy and the eye. The Obstetrician \& Gynaecologist. 2006;8(3):141-6.

4. Qureshi IA, Xi XR, Wu XD. Intraocular pressure trends in pregnancy and in the third trimester hypertensive patients. Acta obstetricia et gynecologica Scandinavica. 1996;75(9):816-9.

5. Garg P, Aggarwal P. Ocular changes in pregnancy. Nepalese Journal of Ophthalmology. 2012;4(1):150-61.

6. Maris PJ, Mandal AK, Netland PA. Medical therapy of pediatric glaucoma and glaucoma in pregnancy. Ophthalmology Clinics. 2005;18(3):461-8.

7. Brauner SC, Chen TC, Hutchinson BT, Chang MA, Pasquale LR, Grosskreutz $\mathrm{CL}$. The course of glaucoma during pregnancy: a retrospective case series. Archives of Ophthalmology. 2006;124(8):1089-94.

8. Vaideanu D, Fraser S. Glaucoma management in pregnancy: a questionnaire survey. Eye. 2007;21(3):341-3.

9. Salim S. Glaucoma in pregnancy. Current opinion in ophthalmology. 2014;25(2):93-7.

10. Thorne JE, Suhler E, Skup M, Tari S, Macaulay D, Chao J, Ganguli A. Prevalence of noninfectious uveitis in the United States: a claims-based analysis. JAMA ophthalmology. 2016;134(11):1237-45.

11. Rabiah PK, Vitale AT. Noninfectious uveitis and pregnancy. American journal of ophthalmology. 2003;136(1):91-8.

12. Chiam NP, Hall AJ, Stawell RJ, Busija L, Lim LL. The course of uveitis in pregnancy and postpartum. British Journal of Ophthalmology. 2013;97:1284-8.

13. Chiam NP, Lim LL. Uveitis and gender: the course of uveitis in pregnancy. Journal of ophthalmology. 2014;2014.

14. Chan CC, Reed GF, Kim Y, Agrón E, Buggage RR. A correlation of pregnancy term, disease activity, serum female hormones, and cytokines in uveitis. British Journal of Ophthalmology. 2004;88(12):1506-9.

15. Koren G. Mycophenolate mofetil. Canadian Family Physician. 2008;54(8):1112-3.

16. Wakefield D, El-Asrar AA, McCluskey P. Treatment of severe inflammatory eye disease in patients of reproductive age and during pregnancy. Ocular immunology and inflammation. 2012;20(4):277-87.

17. Best RM, Chakravarthy U. Diabetic retinopathy in pregnancy. British journal of ophthalmology. 1997;81(3):249-51.

18. Sunness JS. The pregnant woman's eye. Survey of ophthalmology 1988;32(4):219-38.

19. Diabetes Control and Complications Trial Research Group. Effect of pregnancy on microvascular complications in the diabetes control and complications trial. The Diabetes Control and Complications Trial Research Group. Diabetes care. 2000;23(8):1084-91.

20. Lopez-Lopez F, Gomez-Ulla F, Rodriguez-Cid MJ, Arias L. Triamcinolone and bevacizumab as adjunctive therapies to panretinal photocoagulation for proliferative diabetic retinopathy. ISRN ophthalmology. 2012; 2012.

21. Kitzmiller JL, Aiello LM, Kaldany A, Younger MD. Diabetic vascular disease complicating pregnancy. Clinical obstetrics and gynecology. 1981;24(1):107-23.

22. Kearns PP, Dhillon BJ. Angle closure glaucoma precipitated by labour. Acta ophthalmologica. 1990;68(2):225-6.

23. Tang RA, Dorotheo EU, Schiffman JS, Bahrani HM. Medical and surgical management of idiopathic intracranial hypertension in pregnancy. Current neurology and neuroscience reports. 2004;4(5):398-409.

24. Durcan PJ, Corbett JJ, Wall M. The incidence of pseudotumor cerebri: population studies in lowa and Louisiana. Archives of Neurology. 1988;45(8):8757.

25. Markey KA, Mollan SP, Jensen RH, Sinclair AJ. Understanding idiopathic intracranial hypertension: mechanisms, management, and future directions. The Lancet Neurology. 2016;15(1):78-91.
26. Lueck CJ, Mcllwaine GG. Idiopathic intracranial hypertension. Practical neurology. 2002;2(5):262-71.

27. Digre KB, Varner MW, Corbett JJ. Pseudotumor Cerebri and Pregnancy. Obstetrical \& Gynecological Survey. 1985;40(9):575-6.

28. Daniels AB, Liu GT, Volpe NJ, Galetta SL, Moster ML, Newman NJ, Biousse V, Lee AG, Wall M, Kardon R, Acierno MD. Profiles of obesity, weight gain, and quality of life in idiopathic intracranial hypertension (pseudotumor cerebri). American journal of ophthalmology. 2007;143(4):635-41.

29. Koontz WL, Herbert WN, Cefalo RC. Pseudotumor cerebri in pregnancy. Obstetrics \& Gynecology. 1983;62(3):324-7.

30. Katz VL, Peterson R, Cefalo RC. Pseudotumor cerebri and pregnancy. American journal of perinatology. 1989;6(04):442-5.

31. Huna-Baron R, Kupersmith MJ. Idiopathic intracranial hypertension in preg nancy. Journal of neurology. 2002;249(8):1078-81.

32. Wall M, Hart WM, Burde RM. Visual field defects in idiopathic intracranial hypertension (pseudotumor cerebri). American journal of ophthalmology. 1983;96(5):654-69.

33. Evans RW, Friedman DI. The management of pseudotumor cerebri during pregnancy. Headache: The Journal of Head and Face Pain. 2000;40(6):495-7.

34. Della-Giustina K, Chow G. Medications in pregnancy and lactation. Emergency medicine clinics of North America. 2003;21(3):585-613.

35. Percy AK, Nobrega FT, Kurland LT. Optic neuritis and multiple sclerosis: an epidemiologic study. Archives of Ophthalmology. 1972;87(2):135-9.

36. Balcer LJ. Optic neuritis. New England Journal of Medicine. 2006;354(12):1273-80.

37. Optic Neuritis Study Group. The clinical profile of optic neuritis: experience of the Optic Neuritis Treatment Trial. Arch Ophthalmol. 1991;109:1673-8.

38. Liu GT. Visual loss: optic neuropathies. In: Liu GT, Volpe NJ, Galetta SL, eds. Neuro-ophthalmology: diagnosis and management, Philadephia: WB Saunders; 2001:103-87.

39. Wayman D, Carmody KA. Optic Neuritis Diagnosed by Bedside Emergency Physician- Performed Ultrasound: A Case Report. The Journal of emergency medicine. 2014;47(3):301-5.

40. Rodriguez M, Siva A, Cross SA, O'brien PC, Kurland LT. Optic neuritis A population-based study in Olrnsted County, Minnesota. Neurology. 1995;45(2):244-50.

41. Rizzo JF, Lessell S. Optic neuritis and ischemic optic neuropathy: overlapping clinical profiles. Archives of Ophthalmology. 1991;109(12):1668-72.

42. Frohman EM, Frohman TC, Zee DS, McColl R, Galetta S. The neuro-ophthalmology of multiple sclerosis. The Lancet Neurology. 2005;4(2):111-21.

43. Confavreux C, Hutchinson M, Hours MM, Cortinovis-Tourniaire P, Moreau T. Rate of pregnancy-related relapse in multiple sclerosis. New England Journal of Medicine. 1998;339(5):285-91.

44. Birk K, Ford C, Smeltzer S, Ryan D, Miller R, Rudick RA. The clinical course of multiple sclerosis during pregnancy and the puerperium. Archives of Neurology. 1990;47(7):738-42.

45. Sadovnick AD, Eisen K, Hashimoto SA, Farquhar R, Yee IM, Hooge J, Kastrukoff L, Oger JJ, Paty DW. Pregnancy and multiple sclerosis: a prospective study. Archives of neurology. 1994;51(11):1120-4.

46. Van Walderveen MA, Tas MW, Barkhof F, Polman CH, Frequin ST, Hommes OR, Valk J. Magnetic resonance evaluation of disease activity during pregnancy in multiple sclerosis. Neurology. 1994;44(2):327.

47. Poser S, Poser W. Multiple sclerosis and gestation. Neurology. 1983;33(11):1422-

48. Lu E, Wang BW, Guimond C, Synnes A, Sadovnick D, Tremlett H. Diseasemodifying drugs for multiple sclerosis in pregnancy A systematic review. Neurology. 2012;79(11):1130-5.

49. Geissbühler $Y$, Butzkueven $H$, Hernandez-Diaz S, Hellwig K, Koren G, Mac Donald T, Tilson H, Starzyk K, Plana E, Cremer M, von Rosenstiel P. Pregnancy outcomes from fingolimod clinical trials and post-marketing experience and the need for a multinational Gilenya (TM)(fingolimod) Pregnancy Exposure Registry in multiple sclerosis. In Multiple Sclerosis Journal 2012 (Vol 18, pp. 44-44). 1 Olivers Yard, 55 City Road, London, England: Sage Publications Itd.

50. Haghikia A, Rolfes E, Schneider H, Tenenbaum T, Zimmermann J, Marziniak 
M, Kuempfel T, Meinl I, Plavina T, Gold R, Hellwig K. Natalizumb in Active MS during Pregnancy: Efficacy, Safety, and the Consequences for Foetal Haematopoiesis (P02. 125). Neurology. 2013;80(7 Supplement):P02-125.

51. Coyle, Patricia K. Multiple sclerosis in pregnancy. CONTINUUM: Lifelong Learning in Neurology. 2014;20(1):42-59.

52. Chung CY, Kwok AK, Chung KL. Use of ophthalmic medications during pregnancy. Hong Kong Medical Journal. 2004;10(3):191-6.

53. Manufacturer's Information: Azopt product monograph. Texas: Alcon Ophthalmics, Fort Worth, April 1998.

54. Donoway T, Mandeville J, Gauer R. When a fetus survives methotrexate exposure. J Fam Pract. 2012;61(3):E1-4.

55. Kirshon B, Wasserstrum N, Willis R, Herman GE, McCabe ER. Teratogenic effects of first-trimester cyclophosphamide therapy. Obstetrics \& Gynecology. 1988;72(3):462-3.

56. Natekar A, Pupco A, Bozzo P, Koren G. Safety of azathioprine use during pregnancy. Canadian Family Physician. 2011;57(12):1401-2.

57. Drugs.com. [Internet]. 2017 [cited 2017 Jul 10]. Available at: www.drugs. com.

58. Falardeau J, Lobb BM, Golden S, Maxfield SD and Tanne E. The use of acetazolamide during pregnancy in intracranial hypertension patients. Journal of Neuro-Ophthalmology. 2013;33(1):9-12.

59. Friend S, Richman S, Bloomgren G, Cristiano LM, Wenten M. Evaluation of pregnancy outcomes from the Tysabri (natalizumab) pregnancy exposure registry: a global, obersvational, follow-up study. BMC neurology. 2016;16(1):150.

60. Kieseier BC, Benamor M. Pregnancy outcomes following maternal and paternal exposure to teriflunomide during treatment for relapsing-remitting multiple sclerosis. Neurology and therapy. 2014;3(2):133-8. 